\title{
ENSINO SUPERIOR A DISTÂNCIA: REGULAMENTAÇÃO E PERSPECTIVAS NO BRASIL
}

\author{
DISTANCE HIGHER EDUCATION: REGULATION AND PERSPECTIVES
}

\section{Patrícia Maria Medeiros de Andrade}

Universty Sustainable Development-Uds, Asunción, Paraguai. E-mail: patriciamaria.as@hotmail.com

Resumo: O objetivo deste artigo é enfatizar alguns conceitos da Educação a Distância (EaD), apresentar um panorama histórico no Brasil, pontuando a legislação que embasa essa modalidade de educaçáo bem como o cenário atual, de modo a entender a origem e sua finalidade como modelo de ensino nos dias atuais. Pois o $\mathrm{EaD}$ não se trata de um novo formato de educação, pois o que a diferencia de tempos atrás são as tecnologias aplicadas a cada época, sendo amplamente integrada ao sistema de educação a partir da criaçáo da Lei no 9.394/96. Para essa pesquisa foram utilizados um levantamento bibliográfico. Observou-se que esta modalidade de ensino a distância apresenta desafios e sua superaçáo depende, sobretudo de propostas de atualizaçóes nas regulamentaçôes que beneficie as competências e habilidades dos tutores.

Palavras-chave: Educação a Distância. Ensino Aprendizagem. Legislação.

\begin{abstract}
The aim of this article is to emphasize some concepts of Distance Education (EaD), present a historical overview in Brazil, highlighting the legislation of this type of education as well as the current scenario, in order to understand the origin and its purpose as a teaching model in the current days. Because $\mathrm{EaD}$ is not a new format of education, as what differentiates it from a while ago are the technologies applied at each time, being wi-dely integrated into the education system from the creation of Law $\mathrm{n}^{\circ}$ 9.394/96. For this research, a bibliographic survey and quantitative research through interviews were used. It was observed that this modality of distance learning presents challenges and its overcoming depends, above all, on proposals for updating the regulations that benefit the skills and abi-lities of tutors.
\end{abstract}

Keywords: Distance Education. Teaching Learning. Legislation.

\section{Introduçáo}

Tistoricamente o EaD no Brasil, relata resquícios de ensino a partir dos anos de 1900 no Brasil, mas apenas a partir de 1970 houve seu primeiro registro. É inevitável comentar que a evoluçáo tecnológica beneficiou e facilitou a vida da sociedade de modo geral. Ainda que seja inevitável tal comentário, as discussóes sobre os impactos que acometem em 
determinadas áreas do conhecimento, e mesmo assim a inclusão social ainda não ocorre de forma integra.

Quando falamos em Educação a Distância podemos dizer que ela está ligada diretamente a crescente transformaçáo social, cultural, econômica e política de um pais. Pois os benefícios desta modalidade juntamente com o auxílio de ferramentas tecnológicas vão de encontro com as pessoas transformando-os em alunos. De forma a embasar o processo de ensino aprendizagem, uma vez que é oferecido oportunidades educacionais para aquelas pessoas que não dispuseram ou que foram impedidas de estudar em decorrências das dificuldades em encontrar espeço físico apropriado e disponibilidade de tempo.

O Ensino a Distância por meio das ferramentas tecnológicas oferece flexibilidade, dinâmicas e interatividade de forma paralela e assíncrona utilizando a internet e outras ferramentas interativas.

Para Souto (2007) esclarece que o termo EAD, Educação Aberta e a Distância possuem os mesmos conceitos pois o primeiro é sigla do segundo. No entanto para Chaves (2012) as denominaçôes "Educação a Distância" e "Aprendizagem a Distância" são colocações incorretas, uma vez que o processo de educação e aprendizagem ocorrem no "interior" do indivíduo, tornando-se uma ação abstrata.

Vilaça (2010) usa as denominaçóes EaD e EAD, sem diferenciação pois um dos modelos mais claros da interação entre educação-tecnologia e justamente a Educação a Distância, nas modalidades online e semipresencial.

Em se tratando da legislação do EaD é relatado que apenas a partir de 1994 esta modalidade começou a ser tratado como um real modelo de aprendizagem, partir das conversaçóes iniciais promovidas pela reforma da LDB, sendo efetiva partir do ano de 1996 com a nova LDB Lei no 9.394.

Atualmente percebe-se que o modelo de ensino a distância é uma opção de capacitação, desenvolvimento e crescimento intelectual da sociedade, diferenciando a máo de obra que pesquise, crie e desenvolva situaçóes e organize ambientes que levam a massa ao crescimento sustentável, tão relevante nos dias atuais.

\section{Revisáo de literatura}

\subsection{História da EaD e Regulamentação no Brasil}

No ano de 1904 a EaD tem seu primeiro registro no Brasil, por meio de um curso de datilografia oferecido por um jornal. Tal prática acabou se tornando muito comum entre os departamentos jornalísticos do século XIX, como a educação no nosso país não era algo acessível a todos, uma grande parte da sua populaçáo começou a usar esse modo de ensino para se especializar em profissóes voltadas áreas indústria e para o trabalho artesanal (CARVALHO, 2013).

A evolução econômica e tecnológica que ocorreu e ainda acontece, acabou tornando o Brasil um país cada vez mais industrializado, mudando até mesmo o modo de transmissão de conhecimento, ocorrendo em 1920 a passagem dos primeiros conhecimentos técnicos através 
das emissoras de rádio, e destacando-se em 1923 a Fundação da Rádio Sociedade do Rio de Janeiro como pioneira neste seguimento.

Em 1941 é criado o Instituto Universal Brasileiro que oferecia cursos profissionalizantes a distância e oferecia material impresso enviados por correspondência. Em 1947 o SENAC e o SESC lançam a Universidade do Ar, via ondas de rádio (CARVALHO, 2013).

O marco foi entre as décadas de 1960 e 1970 que foi gerado o Código Brasileiro de Telecomunicaçôes, obrigando as emissoras particulares de televisão a disponibilizarem uma parte da sua grade de programação para os programas educativos.

Neste mesmo período o governo brasileiro estimulou a criação dos canais educativos como a TV cultura e a TV escola, o que também levou a Fundação Roberto Marinho a idealizar e investir em uma serie, que futuramente iria ser chamada de Telecurso 2000, com o foco de aprimorar os conhecimentos em matemática básica, linguagem, história e outros mais específicos (VILAÇA, 2010).

$\mathrm{Na}$ década de 70 os computadores também chegaram nas universidades, porém não eram utilizados como ferramenta com fins educacionais. Fato este mudado em meados dos anos 1990 onde os computadores passaram por mudanças revolucionárias, ganhando maior proporção na educação e também sendo agregado a rede mundial de computadores.

A normalização da EaD deu-se com a criação da lei no 9.394/96 que oficializa a educação a distância no Brasil, como modalidade válida e equivalente para todos os ensinos. Da qual o MEC começou a se estruturar e a credenciar oficialmente as instituiçóes universitárias para a atuação na $\mathrm{EaD}$, favorecendo também a criação dos cursos de pós-graduação nesta modalidade (BATISTA; SOUZA, 2016).

No período dos anos 2000 a 2005 são criadas várias redes de Educação Superior a Distância, com vários programas implantados pelo MEC entre eles destaca-se o direcionado à formação inicial e continuada de professores da rede pública (JÚNIOR et al., 2015).

De acordo com Silveira (2014) a adesão aos cursos superiores na modalidade a distância tem aumentado significativamente a partir dos anos 2000. Em meio a essa realidade, a adesão aos cursos superiores na modalidade a distância tem aumentado significativamente nos últimos anos. Nessa modalidade uma nova função é principiada, o papel do professor adjetivado aqui como tutor, para ajudar esses alunos.

A tutoria a distância atua a partir da instituição, mediando o processo pedagógico junto a estudantes geograficamente distantes, e referenciado aos polos descentralizados de apoio presencial. Sua principal atribuição deste profissional é o esclarecimento de dúvidas através fóruns de discussão pela Internet, pelo telefone, participação em videoconferências, entre outros, de acordo com o projeto pedagógico (BRASIL, 2007).

Segundo autores como Vilaça (2010) e Moore e Kearsley (2013) consideram as geraçôes da modalidade a distância de acordo com suas bases tecnológicas, exposto no quadro1: 
Quadro 1: Geraçôes de EaD e suas Bases Tecnológicas

\begin{tabular}{l|l} 
Geração & \multicolumn{1}{|c}{ Base tecnológica } \\
\hline $1^{\text {o }}$ & Ensino transmitido por materiais impressos via correspondência. \\
$2^{\circ}$ & Utilização de rádio, vídeo, TV e fitas cassetes. \\
$3^{\circ}$ & Universidades abertas: uso de material impresso e TV, rádio, telefone. \\
$4^{\circ}$ & Teleconferência com interatividades de áudio e vídeo. \\
$5^{\circ}$ & Internet: uso de MP3, ambientes virtuais de aprendizagem (AVA) e 3D, vídeos, redes sociais e \\
& fóruns. \\
\hline
\end{tabular}

Fonte: Adaptado de Moore e Kearsley (2013).

De acordo com Batista e Souza (2016) a quinta geração vem a cada dia transformando o modo didático e os conceitos relacionados a $\mathrm{EaD}$. O aluno se torna o responsável pela construção do conhecimento que é mediado pelo professor/tutor.

A popularização em $\mathrm{EaD}$ na contemporaneidade tornou-se uma modalidade que mais oferece cursos de modo formal e informal nos ensinos fundamental, médio, tecnológico, graduação e pós-graduação, por sua facilidade e eficácia na qual o processo de aprendizagem ocorre de maneira planejada e intencional.

A educação a distância é norteada pela LDB - Lei de Diretrizes e Base da Educação Nacional, Lei no $9.394 / 96$, que é regulamentada pelo decreto $n^{\circ} 5.622 / 05$ e normatizada pela portaria no 4.361/04 (BRASIL, 1996). É importante destacar que a qualidade do ensino do projeto da instituiçáo será o objetivo mais importante a ser analisado. Deste modo o MEC por meio da Secretaria de Educação a Distância organizou o documento indicador de qualidade para os cursos de graduação a distância. Para consulta, basta acessar o site do MEC, todos são regulamentados por leis de amparo a educação. No caso dos cursos tecnológicos, ou segunda modalidade, é um processo análogo aos cursos de ensino superior, visto que são uma modalidade dos mesmos.

Considerando que o Brasil é um grande incentivador da educação a distância e sem dúvidas tem importância significativa na educação, pois possibilita uma variedade na aprendizagem atingindo uma demanda de pessoas. Além disso as novas tecnologias que surgem a cada dia, não excluem totalmente as anteriores, mas se completam, favorecendo e oferecendo o direito a igualdade e oportunidades a todos na construção do conhecimento.

A mediação da qual se fala em Chermann e Bonini (2000) está diretamente ligada a atuação do docente quanto ator fundamental nesse processo através do sistema integrador do ensino a distância. Pois segundo Ivashita (2009), a educação à distância não oferece um ensino centrado no professor e sim pautado na capacidade do aluno em superar-se e buscar/construir seu próprio conhecimento, trata-se de um ensino centrado no aluno e em suas necessidades tutor.

Nesta perspectiva o papel do professor modifica-se, com a participaçáo de uma nova personagem atuando no processo educativo: o professor tutor. Ainda de acordo com Ivashita (2009), as palavras-chave para se tratar de EaD são: colaboração, cooperação, coparticipação, pois implicam extrapolar uma visão bancária de educação, ou seja, o professor é o detentor do conhecimento.

Assim, vejamos até que ponto o tutor é mero coadjuvante ou coparticipante no 
desenvolvimento do processo de ensino-aprendizagem. Vejamos também sobre algumas opiniôes sua capacitação pregressa e constante dentro desta ótica.

\subsection{Desafios e possibilidades dos professores como dediadores em EaD.}

A trajetória na $\mathrm{EaD}$ no Brasil é marcada por grandes progressos, ganhando credibilidade e alcançando cada vez mais alunos. De acordo com Saggiomo et al. (2017) os avanços tecnológicos permitiram uma considerável melhoria na qualidade e quantidade do conteúdo e conhecimento das aulas e no número de cursos e instituiçôes nos últimos anos.

O número de alunos matriculados é evidenciado no aumento de cursos nesta modalidade em $\mathrm{EaD}$ conforme dados encontrados na figura 1 do último censo INEP, realizado em 2018 referente ao ano anterior consta um crescimento nas matriculas ao equivalente de $21,2 \%$ do total de matriculas em todo o ensino superior (INEP, 2018).

Figura 1: Evolução do total de matriculas em EaD - Censo EaD - 2018.

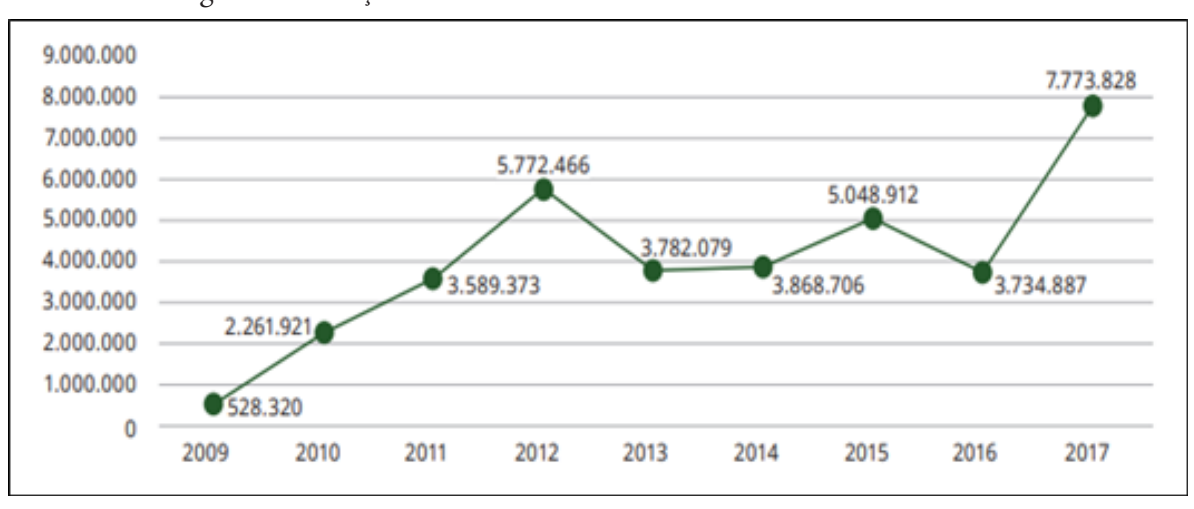

Fonte: INEP, 2018.

Além disso a metodologia nessa modalidade de ensino é um grande atrativo, pois facilita o acesso das pessoas com indisponibilidade para manter sua frequência no ensino presencial por vários motivos. Muitas são as vantagens principalmente porque ela se adequada a realidade dos alunos que buscam uma formação através deste meio. Entretanto, esta escolha leva um grau alto de comprometimento o que no futuro pode acabar se tornando uma desvantagem (COVALSKY; MOTA, 2016).

A EaD exige também uma certa familiaridade com o uso de computadores e uso de internet, contudo, podemos perceber que a $\mathrm{EaD}$ tem muito mais vantagens do que desvantagens, pois o aluno é inserido em um método de ensino que busca formar um aluno consciente, crítico, autônomo e criativo.

Em estudos realizado por Corrêa, Chaquime e Mill (2016), destacam-se que entre os obstáculos apontados pelos tutores durante a tutoria, está a dificuldade do professor-tutor, em transpor de modo claro a proposta pedagógica para a prática. Some-se a isso a dificuldade no uso das tecnologias; a infraestrutura que por vezes é imprópria, relacionado a telecomunicaçóes e a falta de tempo que acaba por dificultar o desenvolvimento de atividades importantes para o progresso do curso. Os tutores consideraram um desafio desempenhar a tutoria, por ser uma experiência nova para a qual não há modelo pré-definido a seguir. 


\section{Metodologia}

O presente estudo científico teve como instrumento de pesquisa uma abordagem de revisão literária de acordo com Gil (2002) partindo de revisóes em literaturas de obras voltadas ao tema estudado, realizando-se um embasamento teórico, metodológico, em artigos, sites, livros e leis objetivando compreender a origem e aplicação desse novo modelo de ensino nos dias atuais no Brasil.

\section{Discussáo e consideraçóes finais}

O tutor ainda não tem uma função pré-estabelecida a ser seguida, mesmo ocupando um papel indispensável na formação dos alunos da $\mathrm{EaD}$. Em linhas gerais, as pesquisas apontam para a atuação do tutor em EaD como mediador da comunicação de conteúdo, dando suporte ao professor formador da disciplina, fornecendo o feedback do desenvolvimento de cada aluno individualmente, estabelecendo contato direto com os alunos e participando do processo de avaliação (SILVEIRA, 2014).

A Educação a Distância é uma forma de ensino que possibilita a autoaprendizagem, com a mediação de recursos didáticos sistematicamente organizados, apresentados em diferentes suportes de informação, utilizados isoladamente ou combinados e veiculados pelos diversos meios de comunicação. Os meios de comunicação são os responsáveis pela alteração do conceito de presencialidade do educador (presença física), assim como a sua responsabilidade do "ensinar".

Neste sentido, a figura determinante no papel do tutor em $\mathrm{EaD}$, está atrelada constantemente a organização em meios tecnológicos estratégicos, visando suprir as mais variadas realidades e necessidades no meio acadêmico em que os alunos estão inseridos. $\mathrm{O}$ processo de aprendizagem online possibilita o desenvolvimento das habilidades virtuais o que exige comprometimento e sem sombra de dúvidas total disciplina com intuito de aumentar o engajamento dos alunos com responsabilidade e eficiência.

A profissionalização pedagógica dos tutores educadores envolvidos em modalidades $\mathrm{EaD}$ e semipresenciais é de extrema importância na trajetória de vida acadêmica dos discentes inseridos nestas modalidades de aprendizagens, possui um papel pautado na participação ativa e acompanhamento diário no processo de andamento dos cursos superiores e graduação.

Esses profissionais passam a ser a ponte e referência de informaçóes concretas para que o aluno tenha total segurança e eficácia em seu curso, buscar adquirir capacitação em inovaçóes principalmente tecnológicas transforma o tutor em eficiente e dinâmico pronto a contribuir com todo conteúdo a ser trabalhado na academia.

Na certeza que a educação a distância vem se desenvolvendo cada vez mais nos dias atuais, os tutores em $\mathrm{EaD}$ passam a consolidar um papel em formador de profissionais críticos atuantes e comprometidos para atuarem com competência no mercado de trabalho, desenvolvem uma outra realidade pelo fato da disciplina o qual adaptaram na graduação, visto que ambos, tutores e alunos revolucionam com saberes na construção de um modelo de educação.

A didática é o principal instrumento do professor: é o que define a qualidade do processo de ensino que ele pode oferecer ao seu aluno. Incentivar a participaçáo, motivar o aluno, induzi-lo a refletir, saber orientá-lo na busca de objetivos, demonstrar comprometimento com a atividade 
de aprendizagem, desenvolver um bom processo de comunicação (MOORE; KEARSLEY, 2013)

Neste contexto, realizar o processo de tutoria em $\mathrm{EaD}$, torna-se um exercício diário na busca pelo conhecimento em inovações didáticas e tecnológicas, exponho em pesquisa cientifica, inquietaçôes acerca de constantes capacitaçôes pedagógicas como emergentes em instituiçôes nas modalidades em ensino a distância, sendo um fator primordial a ser trabalhado com esta demanda de profissionais.

A participação ativa dos tutores em treinamentos, palestras, cursos com temáticas especificas em $\mathrm{EaD}$ e afins, apresenta um diferencial elevado na formação do corpo discente como um todo, diz respeito aos benefícios e métodos a serem aplicados como teorias e práticas de aprendizagem no sentido de formar profissionais competentes socializando saberes intelectuais em todos os sentidos.

As obras literárias analisadas apresentaram relevância do papel do tutor na educação a distância, apresentando suas atribuições de maneira mais definida, abordou sua influência na mediação entre o aluno e o conhecimento, pontuou alguns desafios superados pelo tutor visando melhorar seu atendimento aos clientes como outros professores formadores nas disciplinas e aos alunos que ambienta virtualmente para aprendizagem.

Podemos considerar que um dos principais elementos dessa ideia pedagógica é a impossibilidade da transmissão do conhecimento como hoje ainda se postula. Deve-se considerar que a aprendizagem ocorre em nível individual, dependente, e um trabalho extensivo desenvolvido pelo aluno, com o apoio das redes sociais e a orientação de uma atividade de acompanhamento. Para o nosso estudo, essa possibilidade é colocada como condição para a efetivação de um processo eficaz.

Partindo desse pressuposto, tanto tutores como discentes são atores principais e essenciais no processo de ensino e aprendizagem, sendo fator determinante favorecendo a prática incessante da busca pelo conhecimento, reforçando desta forma a verdadeira importância dos recursos tecnológicos em informação voltada ao ambiente virtual de aprendizagem.

Observou-se que o profissional tutor em EaD, deve possuir, além do conhecimento na modalidade e tecnológico, autonomia para construção de forma efetiva garantindo satisfação ao educando em sua jornada acadêmica, visando assim um futuro promissor no contexto profissional e pessoal, temos neste profissional um incentivador no desempenho do aluno assim como sua equipe multidisciplinar.

Procurando estabelecer uma compreensão mais aprofundada e científica para alcançar os objetivos desta pesquisa, primeiramente houve a exploração da literatura que trata desde assunto relacionado com a Educação a Distância e o papel do tutor neste processo educacional, como bases para desenvolver resultados as questôes centrais e específicas.

Como resultado observou-se que há diversas nomenclaturas para descrever o trabalho do profissional docente atuante como tutor em educação a distância. Essa variedade de nominaçôes encontrada na literatura demonstrou apenas um dos sinais que indicam a falta de critérios para situar a importância deste trabalho, bem como seus processos, conceitos, diretrizes.

O debate merece ser ampliado e continuado, enquanto firma-se no senso comum a figura do tutor com compromisso para ofertar uma educaçáo pautada numa busca por capacitaçáo constante, infraestrutura melhorada, e que sejam contemplados com políticas públicas e maior 
atenção a constante capacitação na área, para que possa dar suporte pedagógico a todos os envolvidos.

\section{Referências}

BATISTA, Carla Jeane Farias; SOUZA, Marisa Magalhães. A Educação a Distância no Brasil: regulamentação, cenários e perspectivas. Revista Multitexto, [S.l.], v. 3, n. 2, p. 11-15, fev. 2016. ISSN 2316-4484. Disponível em: <http://www.ead.unimontes.br/multitexto/index. php/ rmcead/article/view/136>. Acesso em: 08 jul. 2019.

BRASIL. Ministério da educação. Lei n ${ }^{\circ}$ 9.394, de 20 de dezembro de 1996, que dispóes sobre a Diretrizes e Bases da Educação. Disponível em <www.mec.gov.br >acesso em: 06 jul. 2019.

BRASIL. Ministério da Educação. Referenciais de qualidade para educação superior à distância. Brasília, 2007. Disponível em: <http://portal.mec.gov.br/seed/index.php?option= com_content\&-task=view\&id=248\&Itemid=426>. Acesso em: 10 jul. 2019.

CARVALHO, Adélia Honório de. A EVOLUÇÃO HISTÓRICA DA EDUCAÇÃO A DISTÂNCIA NO BRASIL: AVANÇOS E RETROCESSOS. 2013. 36 f. Monografia (Especialização) - Curso de Especialista na Pós-Graduação em Educação, Universidade Tecnológica Federal do Paraná - UTFPR, Medianeira, 2013.

CHAVES, Eduardo OC. Tecnologia na educação, ensino a distância, e aprendizagem mediada pela tecnolgia. Revista de Educação PUC-Campinas, n. 7, 2012.

CHERMANN, Maurício \& BONINI, Luci Mendes. Educação a distância. Novas tecnologias em ambientes de aprendizagem pela Internet. Universidade Braz Cubas, 2000.

CORREAA, André Garcia; CHAQUIME, Luciane Penteado; MILL, Daniel. APRENDIZAGEM DA DOCÊNCIA VIRTUAL: analisando investigaçôes sobre a base de conhecimento docente para Educação a Distância. In: SIMPÓSIO INTERNACIONAL DE EDUCAÇÃO A DISTÂNCIA E ENCONTRO DE PESQUISADORES EM EDUCAÇÃO A DISTÂNCIA (SIED:ENPED), 3., 2016, São Paulo. Anais... SIED: ENPED, 2016. p. 1 12.

COVALSKY, Cristiana Mariani; MOTA, Junior Cesar. Limites e possibilidades de estudantes na educação a distância (EaD). Revista da UNIFEBE, [S.I.], v. 1, n. 18, p. 75-87, dez. 2016. ISSN 2177-742X. Disponível em: <https://periodicos.unifebe.edu.br/index.php/revista eletronicadaunifebe/article/view/399>. Acesso em: 10 jul. 2019.

GIL, Antônio Carlos. Como elaborar projetos e pesquisas. Atlas, São Paulo. 2002.

INSTRUMENTO DE AVALIAÇÃO PARA AUTORIZAÇÃO DE CURSOS DE GRADUAÇÃO (INEP), CENSO 2018. Disponível em: <http://portal.mec.gov.br/par/193secretarias-112877938/seed-educacao-a-distancia-96734370/12777 referenciais-de-qualidadepara-ead>. Acesso em: 07 jul. 2019.

IVASHITA, Simone Burioli; VIEIRA, Renata de Almeida. Os antecedentes do Manifesto dos Pioneiros da Educação Nova (1932). In: SEMINÁRIO NACIONAL DE ESTUDOS E PESQUISAS “HISTÓRIA, SOCIEDADE E EDUCAÇÃO NO BRASIL”, 8., 2009, Campinas, SP. Resumos. Disponível em: <http://www.histedbr.fe.unicamp.br/acerhistedbr/ 
seminario /seminario8/files/GuEVnTfr.pdf > . Acesso em: 12/05/2020.

MOORE. Michael G.; KEARSLEY, Greg. Educação a distância: sistemas de aprendizagem online. 3. ed. São Paulo: Cengage Learning, 2013.

SAGGIOMO, Leandro da Silva et al. Formação continuada em educação a distância: ação e reflexão sobre as competências do professor tutor. Ensino \& Pesquisa, [S.1.], mar. 2017. ISSN 2359-4381. Disponível em: <http://periodicos.unespar.edu.br/index.php/ensinoepesquisa/ article/view/1025>. Acesso em: 08 Jul. 201jul.

SILVEIRA, Cláudia Alexandra Bolela. MEDIAÇÃO PEDAGÓGICA E EDUCAÇÃO A DISTÂNCIA: as competências do tutor e a motivação para aprendizagem. ESUD 2014 - XI Congresso Brasileiro de Ensino Superior a Distância. Florianópolis/SC, agosto v. 19, 2014.

SOUTO, D. J. P. Educação à distância: concepção e formação de professores na sociedade do conhecimento. In: As concepçôes de educação à distância dos professores do CEAD/ ISE/UNIMONTES. Monografia (graduação). Capítulo I. Centro de Ciências Humanas, Universidade Estadual de Montes Claros, Montes Claros, 2007.

VILAÇA, Márcio Luiz Côrrea. Educação a distância e tecnologias: conceitos, termos e um pouco de história. Revista Magistro, Duque de Caxias, v. 2, n. 1. 2010. Disponível em: <http://publicacoes.unigranrio.edu.br/index.php/magistro/article/view/1197>. Acesso em: 05 jul. 2019. 